\title{
KONTRIBUSI KEARIFAN LOKAL YOGYAKARTA: METODE MEMILIH KAYU BAGI DESAIN PRODUK UNTUK INTERIOR
}

\author{
Setya Budi Astanto \\ Program Studi Desain Interior ISI Yogyakarta \\ E-Mail: gilda.pinteriors@gmail.com
}

\begin{abstract}
A local wisdom of Yogyakarta contains a method on how to choose the good wood just by looking at a glance the silhouette of the wood. This method is easy and can be implemented by every person without a special supporting tool.It's better for an interior designerto understand local widom in his closest environment to offer an optimal to the surrounding environment. Meanwhile, global environment problems are everybody's responsibility so that it will be better if everybody can make a contribution in offering a design solution to the surrounding environmental problem.

The qualitative method in this research collected all the significant data from informants comprising both narrative and visual ones. This research is relevant to the present urban community's environmental requirements, especially about how to prevent threat to trees in rural area. By this research a lot of people is expected to understand why nailing trees or scratching them are forbidden because trees that have been hurted will produce bad timbers. Based on this conditions interior designers should have smart solutions using nature as their inspirations; this is commonlycalled biomimicry design.
\end{abstract}

Keywords: sustainble interior design, biomimicry, local wisdom of Yogyakarta, method of choosing log timber.

\section{ABSTRAK}

Kearifan lokal dari Yogyakarta ternyata memperlihatkan cara memilih kayu gelondong utuh yang isinya baik atau tidak berlubang maupun rusak hanya dengan cara melihat sepintas dari wujud siluet kayu tersebut. Cara ini sangat mudah dan sangat bermanfaat untuk diaplikasikan oleh setiap orang tanpa memerlukan alat bantu khusus. Desainer Interior sebaiknya memahami kearifan lokal dilingkungan terdekatnya untuk memberikan solusi yang optimal bagi problem di sekitarnya. Problem lingkungan skala global adalah tanggung jawab setiap orang, sehingga alangkah baiknya jika setiap orang bisa berkontribusi memberikan solusi desain bagi problem desain di lingkungan sekitarnya. Metode kualitatif dalam penelitian ini $b$ er u p ay a men g u mp u lk an s emu a d ata pendukung dari informan baik berupa informasi lisan maupun data gambar yang mendukung penelitian ini. Penelitian ini sesuai kebutuhan masyarakat urban terkini, terutama bagaimana mencegah ancaman terhadap pohon di wilayah pedesaan. Lewat penelitian ini diharapkan banyak orang memahami bahwa menancapkan paku pada pohon atau melukai pohon tersebut adalah dilarang karena pohon yang terluka akan menghasilkan kayu yang jelek. Berdasarkan kondisi ini, desainer interior harus memiliki solusi-solusi cerdas menggunakan alam sebagai inspirasi; inilah yang secara umum disebut desain biomimikri. 
Kata kunci:desain Interior berkelanjutan, biomimikri, kearifan lokal Yogyakarta, metode memilih kayu gelondongan.

\section{Keistimewaan Material Kayu}

Kayu adalah material istimewa karena mempunyai kecengakahan secara ilmiah berkaitan dengan perubahan kimia material kayu yang khas. Kayu adalah salah satu material dominan dalam industri desain interior yang tidak meleleh saat dibakar.Kayu adalah salah satu benda padat yang berbeda dari material padat lain terutama saat benda padat ini dipanaskan,sebagai contoh material bongkahan es akan mencair saat dipanaskan, batang besi akan meleleh dan mencair saat dipanaskan layaknya pada proses pencetakan besi, serta lava yang mengalir kemudian mendingin jadi batu. Intinya kebanyakan benda padat mencair bila dipanaskan, hanya saja kita jarang melihatnya dalam wujud cair karena ia hanya terjadi dalam suhu sangat tinggi. Sebaliknya berbagai jenis gas bisa dicairkan bahkan dipadatkan, namun hanya bisa disaksikan pada suhu yang sangat rendah. Tapi apakah kayu bisa mencair kalau dipanaskan? Tidak. Kenapa? Pertama, kayu tidak tersusun dari bahan tunggal atau homogen seperti air dan besi.Kayu tersusun oleh berbagai jenis molekul sepertj selulosa, lignin, parafin, dan sebagainya. Kayu juga mengandung air, saat kayu kita panaskan sebagian dari bahan tersebut mencair dan menguap.Pengalaman di kampung dulu kalau memasak dengan kayu bakar, di ujung kayu yang tidak sedang terbakar sering keluar air atau uap air, juga parafin atau getah kayu yang meleleh.Tidak semua bagian kayu meleleh sebagian besarnya mengalami perubahan yang bukan perubahan fisika, tapi perubahan kimia.
Perubahan fisika adalahperubahan wujud tadi.Intinya benda tersebut hanya berubah wujud, sedangkan ikatan antar atom atau molekul penyusun bahan tidak berubah.Perubahan fisika pada dasarnya bersifat dapat balik. Bila es kita panaskan maka es akan menjadi cair, tapi kalau bila dinginkan kembali maka benda cair itu kembali menjadi es. Pada perubahan kimia sifatnya tidak dapat balik, sebagai contoh adalah bila kertas kita bakar, kertas tidak bisa berubah w u j d menjadi kertas lagi.Pembakaran adalah salah satu contoh perubahan kimia.Pada perubahan kimia ikatan antar molekul putus, kemudian terbentuk ikatan baru.Hal ini juga disebut reaksi kimia.Gas hidrogen bereaksi dengan oksigen menghasilkan air yang tidak lagi membawa sifat hidrogen dan oksigen.

Ketika kayu dipanaskan di ruang terbuka, ia akan bereaksi dengan oksigen, ini yang kita sebut pembakaran. Pembakaran terjadi pada suhu pembakaran atau titik bakar (Combustion / fire point temperature)adalah temperatur di mana bahan yang dinyalakan akan terbakar terus menerus apabila diberi sumber panas, biasanya kira-kira $30-40{ }^{\circ} \mathrm{C}$ lebih tinggi dari titik nyala.Suhu pembakaran kayu lebih rendah daripada suhu titik leburnya, sehingga kita tidak bisa menyaksikan kayu meleleh, karena kalau dipanaskan ia akan terbakar.Bagaimana jika material kayu dipanaskan tanpa oksigen, karena kayu tersusun dari molekul yang terdiri dari hidrogen, oksigen, nitrogen, dan karbon. Bila dipanaskan maka atom-atom dengan tenaga ikat rendah yaitu hidrogen, oksigen, dan nitrogen akan putus ikatan, selanjutnya menguap sehingga yang tersisa tinggal karbon. Dalam bahas a sehari kita menyebutnya arang (Elise, 2013: 15). 


\section{Kearifan Lokal Yogyakarta Berkaitan Material Kayu}

Material kayu menempati posisi sangat penting dalam dunia arsitektur dan desain in terior di khasanahmasyarakat Yogyakarta.Kayu sangat dekat dengan masyarakat beriklim tropis sejak dahulu kala, selain sumber daya alam yang melimpah kayu mempunyai sifat sangat fleksibel.Masyarakat Yogyakarta sangat mahir dalam merekayasa material kayu, mulai material kayu sebagai bahan kontruksi, pembentuk arsitektur, dan elemen desain interior.Pemahaman yang mendalam tentang material kayu ini menghasilkan kearifan lokal yang dikumpulkan dari uji coba selama bertahuntahun melalui ujian waktu dan kondisi. Catatan tentang kelebihan dan keunggulan material kayu menghasilkan kearifan lokal yang mapan dalam melakukan klasifikasi material kayu, baik kayu yang dianggap baik maupun buruh, kayu yang bernilai tinggi dan bernilai fungsi, bahkan masyarakat
Yogyakarta mempunyai kearifan lokal tentang kayu dan dampak bagi kehidupan manusia dan lingkungannya.

Kearifan lokal Yogyakartadengan sangat baik mengenal secara baik dan sistematis dalam kehidupan sehari-hari yang diamalkan secara turun-temurun, tentang peran vital kualitas material kayu maupun proses memanen kayu.Dalam kearifan lokal Yogyakarta yang merupakan bagian dari budaya Jawa Tengah, material kayu dianggap mengandung juga sifat-sifat baik atau kurang baik bagi kehidupan manusia sebagai pengguna kayu.Sifat ini mendapat perhatian serius secara turun temurun, terutama bila masyarakat hendakmenggunakan bahan kayu tersebut untuk membangun rumah.Sifat-sifat kayu mendapatkan perhatian ekstra terutama pada kayu jati dengan ciri-ciri khas yang berhubungan dengan sosok tubuh atau tempat tumbuhnya.Kayu jati yang dianggap bertuah atau baik adalah sebagai berikut.

\begin{tabular}{|l|l|}
\hline \multicolumn{2}{|l|}{ Daftar kayu jati yang dianggap bertuah atau baik } \\
\hline Uger-uger* & $\begin{array}{l}\text { Kayu jati yang batangnya bercabang dua. Apabila kayu ini dipakai sebagai } \\
\text { bahan bangunan rumah, penghuninya senantiasa akan hidup rukun damai; } \\
\text { lebih-lebih jika penggunaannya sebagai uger-uger pintu rumah, pintu cepuri } \\
\text { (regol), atau pagar pekarangan. }\end{array}$ \\
\hline Trajumas & $\begin{array}{l}\text { Kayu jati satu batang/pohon yang bercabang tiga. Bila kayu jati ini digunakan } \\
\text { untuk bahan bangunan, penghuninya akan banyak rezeki. Pemakaian yang } \\
\text { tepat ialah sebagai kerangka rumah yang berada di atas atau bagian rumah } \\
\text { sebelah atas, misalnya blandar, pengerat, molo, dsb. }\end{array}$ \\
\hline Pandawa* & $\begin{array}{l}\text { Kayu jati satu batang/pohon bercabang lima pada waktu masih hidup. Pada } \\
\text { bangunan yang menggunakan kayu jati ini sebagai bahan, penghuninya } \\
\text { senantiasa berhati teguh atau tabah menghadapi segala masalah atau kesulitan. } \\
\text { Kayu ini sangat tepat untuk bahan bangunan rumah sebagai pendopo, terutama } \\
\text { untuk saka guru. }\end{array}$ \\
\hline
\end{tabular}




\begin{tabular}{|c|c|}
\hline Monggang* & $\begin{array}{l}\text { Kayu jati yang tumbuh di puntuk atau di puncak tanah yang berbukit. } \\
\text { Penghuni bangunan yang menggunakan kayu jati ini, derajatnya akan mudah } \\
\text { naik, bertambah banyak rezekinya. Pemakaian yang tepat ialah untuk } \\
\text { kerangka bangunan regol, bangsal, pesanggrahan, semua rumah tidak } \\
\text { dipergunakan untuk tempat tinggal (tidur), tetapi sekedar tempat } \\
\text { peristirahatan. }\end{array}$ \\
\hline Mulo* & $\begin{array}{l}\text { Istilahnya dari pulo berarti pulau, yaitu kayu jati yang pada waktu masih } \\
\text { hidup dikelilingi oleh air atau tempat tumbuhnya berair, misalnya rawa-rawa } \\
\text { Penghuni rumah dari bahan kayu jati mulo mempunyai sifat berhati tenteram, } \\
\text { sabar dan tabah. Pemakaian yang tepat ialah sebagai bahan kerangka pendopo. }\end{array}$ \\
\hline Tunjung & $\begin{array}{l}\text { Kayu jati ini pada waktu masih hidup ditempati sarang burung dari jenis } \\
\text { burung yang besar, misalnya burung bangau, burung elang, burung gagak, dan } \\
\text { sebagainya, atau ditempati binatang hutan yang besar, misalnya harimau, } \\
\text { gajah, dan sebagainya. Jika kayu ini dipergunakan sebagai bahan bangunan, } \\
\text { penghuninya akan mudah naik pangkat, dan memiliki sifat menjauhkan } \\
\text { perbuatan jahat. } \\
\text { Pemakaian yang tepat ialah untuk kandang kuda, serta kandang ternak lain } \\
\text { seperti kerbau, lembu, dan sebagainya. }\end{array}$ \\
\hline Gendam & $\begin{array}{l}\text { Kayu jati ini pada waktu masih hidup pernah dipakai sebagai sarang dari } \\
\text { Kayu jati ini pada waktu masih hidup pernah dipakai sebagai sarang dari jenis } \\
\text { burung kecil-kecil. Penghuni rumah yang dibangun dengan bahan kayu jati } \\
\text { gendam akan mudah rezeki, banyak kawan. Kayu jati gendam lebih tepat } \\
\text { unutk bahan gedogan atau kandang kuda dan kandang binatang ternak lain, } \\
\text { misalnya kerbau, lembu, untuk alat-alat berburu, tangkep atau alat penangkap } \\
\text { kera, galodok atau rumah lebah madu dan sebagainya. }\end{array}$ \\
\hline Gendong & $\begin{array}{l}\text { Kayu jati ini tumbuh dari anak atau cabang kayu jati induk. Penghuni yang } \\
\text { rumahnya dibangun dari bahan kau jati gendong senantiasa akan banyak } \\
\text { rezeki dari bawahan atau anak buah. Pemakaian kayu jati gendong yang tepa } \\
\text { ialah sebagai bahan rumah gedung, alat untuk menyimpan harta benda, benet, } \\
\text { peti, dan sebagainya. }\end{array}$ \\
\hline Gedeg & $\begin{array}{l}\text { Pada waktu hidupnya, pada kayu jati ini terdapat gambol atau tambi, yaitu } \\
\text { pangkal akar yang melebar dan memanjang pada pokok kayu. Penghuni yang } \\
\text { rumahnya dibangun dari bahan kayu jati gedeg akan memiliki banyak } \\
\text { binatang ternak, memberikan jalan keselamatan. Kayu jati gedeg lebih baik } \\
\text { untuk kandang dan tempat penyimpan barang-barang. }\end{array}$ \\
\hline Gedug & $\begin{array}{l}\text { Kayu jati pada waktu masih hidup terdapat gandik. Penghuni yang rumahnya } \\
\text { dibangun dari bahan kayu jati gedug akan banyak memiliki binatang ternak, } \\
\text { kuat menyimpan harta dunia yang sangat berharga. Penggunaan kayu jati } \\
\text { gedug yang tepat ialah untuk membuat rumah gedung sebagaitempat } \\
\text { penyimpanan hartabenda. }\end{array}$ \\
\hline
\end{tabular}

Tabel1.Kearifan lokal daftar kayu Jati yang dianggap bertuah atau baik

(Sumber: Frick, 1997: 104-105) 
Disamping kayu jati dari pohon-pohon tersebut, ada juga kayu jati yang mengandung pengaruh kurang baik terhadap penghuni rumah, seperti pada table berikut ini:

\begin{tabular}{|c|c|}
\hline \multicolumn{2}{|c|}{ Daftar kayu jati yang mengandung pengaruh kurang baik } \\
\hline $\begin{array}{l}\text { Klabang } \\
\text { pipitan }\end{array}$ & $\begin{array}{l}\text { Kayu jati yang pada waktu masih hidup di dalamnya terdapat bagian yang } \\
\text { berkulit. Sebenarnya kayu jati semacam itu mudah pecah apabila } \\
\text { dipergunakan sebagai bahan bangunan. Penghuni rumah yang menggunakan } \\
\text { kayu jati klabang pipitan senantiasa akan sakit, berarti panas dan tidak } \\
\text { memiliki sifat sabar. }\end{array}$ \\
\hline Tundung & $\begin{array}{l}\text { Kayu jati ini pada waktu diteban atau roboh menimpa pohon jati lain dan masih } \\
\text { hidup di tempat tumbuhnya. Kayu jati yang tertimpa menjadi roboh dan mati. } \\
\text { Penghuni rumah dari bahan kayu jati tundung senantiasa senang memfitnah, } \\
\text { senang berbuat jahat dan perbuatan-perbuatan buruk lainnya. }\end{array}$ \\
\hline Sadang* & $\begin{array}{l}\text { Kayu jati ini pada waktu ditebang atau roboh melintang di sungai, jalan, } \\
\text { jurang, dan sebagainya. Penghuni rumah yang dibuat dari kayu jati sadang, } \\
\text { selalu menemui masalah dan senantaisa mendapat musibah atau penyakit. }\end{array}$ \\
\hline Sondo & $\begin{array}{l}\text { Kayu jati yang pada waktu ditebang atau roboh bersandar pada jati yang lain } \\
\text { dan masih berdiri. Penghuni rumah yang dibuat dari kayu jati sondo mudah } \\
\text { turun derajatnya karena perbuatan orang lain atau mudah mendapat } \\
\text { kecelakaan dari tetangganya. }\end{array}$ \\
\hline Sarah & $\begin{array}{l}\text { Kayu jati ini hanyut oleh air. Sebenarnya yang disebut sarah adalah semua } \\
\text { barang atau kotoran yangdibawa hanyut oleh air banjir atau air sungai. Kayu } \\
\text { jati yang hanyut oleh air disamakan dengan kotoran. Penghuni rumah yang } \\
\text { menggunakan bahan dari kayu jati sarah selalu mendapat kekecewaan, } \\
\text { berkurang rezekinya. }\end{array}$ \\
\hline Sujen terus & $\begin{array}{l}\text { (sujen = lidi semacam tusuk sate) Jenis kayu jatiini pada waktu masih hidup } \\
\text { berlubang tembus pada batangnya. Penghuni rumah dari bahan kayu jati sujen } \\
\text { terus senantiasa akan mudah terkena senjata tajam. }\end{array}$ \\
\hline Mutah ati & $\begin{array}{l}\text { Kayu jati ini terbelah pada waktu masih muda, sehingga setelah pohon } \\
\text { menjadi tua ada bagian dalam batang pohon tersebut yang mencuat keluar. } \\
\text { Penghuni rumah yang menggunakan bahan dari kayu jati mutah ati akan selalu } \\
\text { mempunyai niat kurang baik dan senantiasa terbuka rahasianya. }\end{array}$ \\
\hline Gombang & $\begin{array}{l}\text { Kayu jati ini pada waktu hidupnya terddapat bagian yang terpendam dalam } \\
\text { tanah atau tergenang air. Penghuni rumah yang menggunakan kayu jati } \\
\text { gombang senantiasa tidak tercapai maksudnya, selalu sakit dan mendapat } \\
\text { fitnah. }\end{array}$ \\
\hline Prabatang & $\begin{array}{l}\text { Kayu jati ini roboh tanpa ditebang. Kayu jati prabatang mempunyai pengaruh } \\
\text { selalu menggagalkan maksud baik penghuni rumah dan menurunkan } \\
\text { derajatnya. }\end{array}$ \\
\hline
\end{tabular}




\begin{tabular}{|l|l|}
\hline Galinggang* & $\begin{array}{l}\text { Kayu jati ini mati karena suatu sebab, meskipun pohon tersebut belum tua. } \\
\text { Penghuni rumah yang menggunakan bahan kayu jati galinggang tidak } \\
\text { mempunyai daya kekuatan, selalu gagal maksud baiknya dan sering } \\
\text { mengalami sakit-sakit. }\end{array}$ \\
\hline Gronang & $\begin{array}{l}\text { Kayu jati ini pada waktu roboh (waktu ditebang) menimbulkan suara karena } \\
\text { mendadak atau keras, sehingga membuat terkejut binatang buas sampai } \\
\text { bersuara. Rumah yang menggunakan kayu jati gonang senantiasa mendapat } \\
\text { kata-kata buruk dari pembesar atau mendapat umpatan dari atasan. }\end{array}$ \\
\hline Gandongan & $\begin{array}{l}\text { Kayu jati ini tumbuh dari cabang kayu. Penghuni rumah dari bahan kayu jati } \\
\text { gandongan akan selalu berniat jahat. }\end{array}$ \\
\hline Gosong & $\begin{array}{l}\text { Kayu jati ini mati karena terbakar. Penghuni rumah yang menggunakan kayu } \\
\text { jati gosong akan sering mendapat musibah bahaya kebakaran. }\end{array}$ \\
\hline Gronggang & $\begin{array}{l}\text { Kayu jati ini roboh tanpa ditebang atau pada waktu roboh ditebang tersangkut } \\
\text { pada dahan pohon jati lain. Penghuni rumah yang menggunakan kayu jati } \\
\text { gronggang akan selalu gagal maksudnya karena terhalang oleh pihak lain. }\end{array}$ \\
\hline Buntel mayit & $\begin{array}{l}\text { (buntel = bungkus; mayit = mayat) Di dalam kayu jati terdapat bagian rapuh } \\
\text { atau bagian yang mati pada waktu pohonnya masih hidup. Penghuni rumah } \\
\text { yang menggunakan bahan kayu jati buntel mayit akan sekalu menderita } \\
\text { penyakit dalam melakukan tugas. }\end{array}$ \\
\hline
\end{tabular}

Tabel 2.Kearifan lokal daftar kayu mengandung pengaruh kurang baik (Sumber: Frick, 1997: 107-108)

Dari semua paparan sumber pustaka karya Heinz Frick tentang kearifan lokal Yogyakarta tersebut, analisa peneliti menemukan adanya klasifikasi kayu yang baik dan kayu yang kurang baik, bahkan ada klasifikasi kayu yang membahayakan keselamatan manusia.Istilah kayu Sujen Tembus dan Buntel Mayit sangat mendapat perhatian serius dalam kearifan lokal masyarakat Yogyakarta karena dianggap mampu menimbulkan akibat buruk bagi penggunanya.Sujen Tembus (sujen = lidi semacam tusuk sate) Jenis kayu jatiini pada waktu masih hidup berlubang tembus pada batangnya. Penghuni rumah dari bahan kayu jati sujen terus senantiasa akan mudah terkena senjata tajam.Buntel Mayit(di dalam kayu jati terdapat bagian rapuh atau bagian yang mati pada waktu pohonnya masih hidup)yang menempatkan kayu tersebut tidak hanya sebagai material sampah, bahkan masuk daftar kayu berbahaya bagi keharmonisan hidup manusia.(Frick, 1997: 108).

Peneliti melihat konsep dasar klasifikasi kayu baik dan kurang baik dalam kearifan lokal Yogyakarta tersebut perlu disikapi secara kritis sebagai solusi agar kayu yang dianggap kurang baik dapat dicegah sejak masa tanam dan tumbuh, dan dapat diotimalkan jika terdapat kayu yang dianggap kurang baik dengan solusi desain yang kreatif dan inovatif bersumber pada sistem alam semesta, terutama berkaitan dengan prinsip dasar desain interior berkelanjutan Biomimikri. Kearifan lokal tentang klasifikasi kayu baik dan buruk tersebut mencerminkan bagaimana kondisi dan situasi pada masa itu yang sangat berlimpah dengan kayu, baik jumlah maupun 
pilihannya, sehingga manusia saat itu masih bisa memilih hanya kayu terbaik yang digunakan.Dalam prinsip desain interior berkelanjutan, manusia harus mempunyai tindakan desain yang bersifat preventif, atau terkenal dengan prinsip Reduce design.Hasil akhir dari kualitas kayu tersebut dapat mengedukasi masyarakat tentang bagaimana perilaku manusia terhadap pohon untuk menghasilkan kayu baik.Kayu yang baik dihasilkan dari campur tangan manusia sejak menanam hingga menebang atau memanen, begitu juga kayu yang kurangd baik atau buruk juga disebabkan ulah manusia juga, misalnya menancapkan paku pada pohon untuk pasang papan iklan, memangkas batang dahan terlalu mepet pokok pohon.Kedua tindakan manusia yang biasanya terjadi pada masyarakat perkotaan tersebut dapat mengakibatkan kayu kurang baik seperti kayu Sujen Tembus dan Buntel Mayit.

Peneliti juga melakukan analisa desain interior yang menunjukkan perlu adanya rekayasa desain interior berkelanjutan Biomimikri untuk melakukan Re-Use design maupun Reduce design. Rekayasa desain tersebut merujuk pada tindakan kreatif desainer terhadap lingkungannya, upaya holistik untuk membuat tidak ada sampah dalam daur hidup pohon dan tidak ada pohon yang menjadi sampah saat proses tumbuh sejak ditanam hingga saat dipanen.

\section{Kearifan Lokal Yogyakarta Berkaitan Metode Memilih Kayu}

Penelitian kearifan lokal masyarakat Yogyakarta tentang metode memilih kayu berhasil mendapatkan data dari hasil wawancara dengan beberapa orang informan beberapa pedagang kayu Jati di beberapa toko kayu di Yogyakarta.Informasi lisan tersebut menjadi sangat penting dalam penelitian ini karena peneliti belum menemukan sumber kearifan lokal tersebut dari data pustaka tertulis.Layaknya sebagian besar kearifan lokal masyarakat Yogyakarta lainnya, hampir sebagian besar bersumber dari data lisan.Sehingga menjadi sangat krusial bagi dunia keilmuan desain interior berkelanjutan untuk mendokumentasikan dalam bentuk informasi tertulis dalam penelitian ini.

Masyarakat Yogyakarta yang berprofesi berkaitan dengan material utama kayu mempunyai kearifan lokal metode memilih kayu yang baik, hanya dengan melihat siluet batang kayu.Kayu yang dianggap baik adalah kayu yang utuh dan tidak ada mata saat dibelah. Untuk membedakan kayu yang utuh dan tidak serta bermata atau tidak masyarakat Yogyakarta tidak perlu membelah kayu tersebut, mereka cukup memilih kayu yang bentuk siluetnya lurus tanpa ada yang mengembung ditengah tengah batang kayu, atau idealnya kayu ukurannya makin ke atas makin kecil secara proporsional.

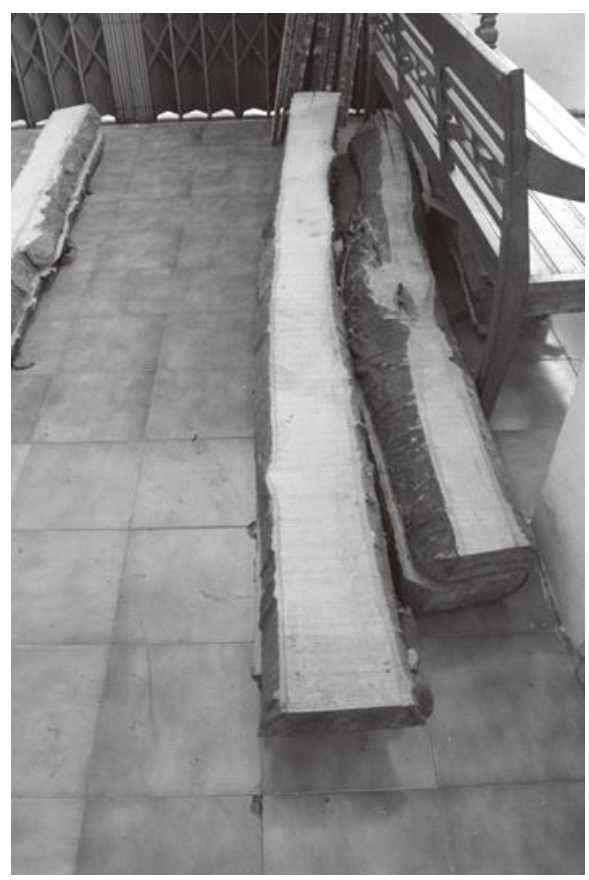

Gambar 1. Sample siluet

kayu pohon Melinjo (Gnetum Gnemon) gelondong normal makin ke atas makin kecil proporsional (Sumber: Koleksi Setyo Budi Astanto) 
Kayu yang bentuk siluetnya mengembung di tengah-tengah biasanya kondisi dalamnya berlubang atau dianggap kayu berkualitas buruk.Anggapan baik dan buruk tentang kualitas kayu ini karena pada umumnya nilai kayu berdasarkan kubikasi, atau dihitung berdasar ukuran volume kayu, jadi jika ada yang berlubang di tengah-tengah kayu maka pembeli menanggung kerugian akibat membayar harga yang lebih mahal untuk mendapatkan jumlah yang lebih sedikit.Kayu gelondong seperti kaki atau tangan tubuh manusia, jika pernah terluka maka akan membengkak permanen sehingga terlihat mengembung atau lebih besar dan dalamnya berongga.

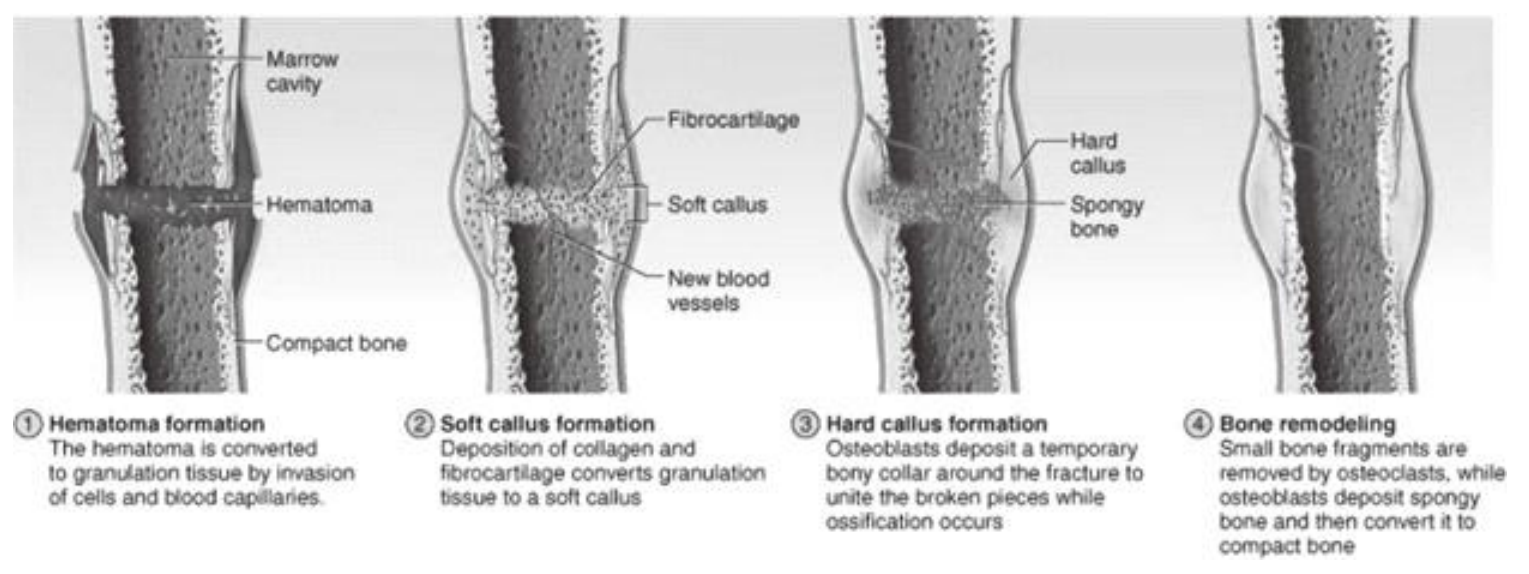

Gambar 2.Tubuh manusia bekas luka patah tulang saat pulih akan bersiluet menggembung tidak lurus proporsional.

(Sumber:https://wholehealthdork.files.wordpress.com/2014/03/fracture-healing.jpg)

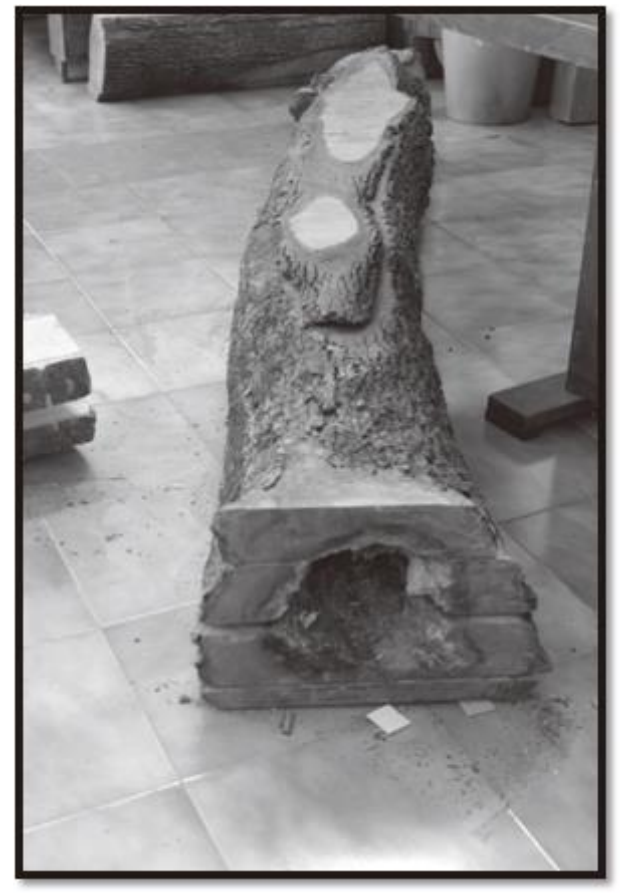

Gambar 3.Sample kayu gelondong bersiluet mengembung mirip ciri ciri tubuh yang pernah terluka patah tulang pada pohon Sawo (Achras Zapota) dengan tampak luar utuh tapi berlobang di dalamnya.

(Sumber: Koleksi Setya Budi Astanto) 
Kearifan lokal Yogyakarta tentang kayu berlobang didalamnya menempatkan kualitas kayu dengan ciri ciri tersebut sebagai material kayu yang berbahaya bagi kehidupan manusia penggunanya. Kearifan lokal tersebut memberi nama jenis kayu yang berlobang tengahnya dengan nama yang cukup menyeramkan yaitu kayu Buntel mayit, buntel artinya bungkus danmayitartinya mayat.Di dalam kayu jati terdapat bagian rapuh atau bagian yang mati pada waktu pohonnya masih hidup. Penghuni rumah yang menggunakan bahan kayu jati buntel mayit akan sekalu menderita penyakit dalam melakukan tugas.(Frick, 1997: 107-108).

Kearifan lokal Yogyakarta dalam menilai dan penamaan Buntel mayitharus kita sikapi dengan kritis, karena kayu berlobang tenggahnya biasanya adalah akibat ulah manusia sendiri yang kurang baik terhadap pohon saat tumbuh, misal menancapkan paku, memotong ranting yang terlalu mepet dengan batang pokok pohon sehingga air hujan masuk ke dalam batang pohon dan menyebabkan busuk di dalamnya, sehingga kayu glondongan berlubang saat dipanen.

Kerugian akibat tidak bisa memilih kayu gelondong yang berlobang dan tidak, adalah hal yang paling sering terjadi dalam dunia perdagangan kayu secara sistemik, secara umum memang akan dikondisikan agar kerugian menimpa konsumen akhir atau desainer interior sebagai pengguna material kayu, kerugian tidak akan menimpa pedagang kayu. Pedagang kayu yang berpengalaman dan mempunyai jaringan kuat tidak membeli kayu gelondong dengan sistem perhitungan kubikasi lewat pengukuran penampang kayu, tetapi pedagang mempunyai sistem pengukuran volume berdasar jumlah daging kayu dengan X pengukuran sistem Symbilium (http://teknologihutan.fkt.ugm.ac.id/userfiles/ download/SNI_7533.2.2011_._Kayu_bundar _Bagian_2_Pengukuran_dan_tabel_isi_pdf).
Sistem Symbilium adalah cara menghitung volume kayu berdasar jumlah daging kayu yang benar-benar ada, caranya adalah dengan menghitung jumlah air yang tumpah dalam bak air super besar setelah menghitung jumlah air yang tersisa setelah sebatang kayu gelondong dimasukkan ke dalam bak air tersebut. Logika yang digunakan adalah jika kayu tersebut berlubang di dalamnya maka bisa dideteksi dari jumlah volume air yang hanya benar-benar tumpah dari bak air.Sistem Symbilium ini digunakan bangsa Belanda untuk mengurangi kerugian akibat selisih nilai kayu jika diukur dengan kubikasi berdasar perhitungan diameter terkecil ujung kayu dikalikan panjang kayu.Kerugian menjadi sangat signifikan jika kubikasi kayu berpenampang paling kecil kondisinya cembung atau membesar sedang $\mathrm{t}$ e $\mathrm{n} \mathrm{g} \mathrm{a} \mathrm{h} \mathrm{k} \mathrm{a} \mathrm{y} \mathrm{u} \mathrm{m} \mathrm{e} \mathrm{n}$ g e c i 1 . (http://bpphp17.dephut.net/database/modul/R umus $\% 20$ Pengukuran $\% 20$ Kayu $\% 20$ Bulat $\% 2$ 0Rimba.pdf).

Kecurangan dalam perdagangan material kayu gelondong diantara pedagang kayu adalah hal yang jamak, sehingga nenek moyang kita mempunyai peribahasa Bermain Kayu yang artinya curang atau tidak jujur.

\section{Kontribusi Kearifan Lokal Yogyakarta Cara Memilih Kayu bagi Desain Interior Berkelanjutan Biomimikri}

Kearifan lokal Yogyakarta tentang metode memilih kayu gelondong utuh atau berlobang di dalamnya adalah dengan meniru sistem alam semesta atau desain Biomimikri, yaitu dengan melihat fenomena bentuk siluet tubuh manusia yang pernah patah tulang karena kecelakaan.Menurut Janine Benyus (2002), desain interior berkelanjutan Biomimikri adalah desain yang mencontoh dari alam atau respek pada alam dan sistem alam semesta, sehingga alam harus menjadi 
panduan dan model bagi proses desain. Sebuah Desain yang mempertimbangkan aspek tanggung jawab desainer terhadap lingkungannya atau Environtment Responsibility Design yangtercermin dari $\mathrm{p}$ enerapan prinsip-prinsip desain berkelanjutan. (Jones: 2008, 4-5).

Conto-contoh dari kayu yang dihasilkan dalam penelitian ini adalah terdapat korelasi antara kearifan lokal Yogyakarta tentang metode memilih kayu gelondong dengan ciriciri berpedoman pada sistem tubuh manusia yang pernah mengalami patah tulang. Tubuh yang pernah patah tulang akan berbentuk mengembung atau tidak rata lagi ketika sudah pulih, begitu juga pohon yang pernah terluka akan menghasilkan kayu gelondong yang berbentuk mengembung dan berlobang di dalamnya.
Dalam penelitian ini ditemukan korelasi antara paradigma masyarakat tentang kayu baik dan kayu buruk adalah terdapat peran perilaku manusia.Kearifan lokal mengajarkan agar kita lebih peduli dan sayang terhadap pohon, tidak menancapkan paku, tidak memotong ranting terlalu mepet pokok pohon.Diperlukan regulasi solutifuntuk menghasilkan material kayu yang diinginkan sejak dari masa pembibitan kayu hingga masa panen tiba. Temuan penelitian juga menghasilkan sebuah solusi berupa alternative rekayasa desain interior berkelanjutan Biomimikri, untuk melakukan optimalisasi dan untuk mencegah timbulnya sampah baru terhadap kayu gelondong yang berlobang tenggahnya. Desain berkelanjutan biomimikri dituntut memberi solusi kreatif mengoptimalkan kayu gelondong berlobang

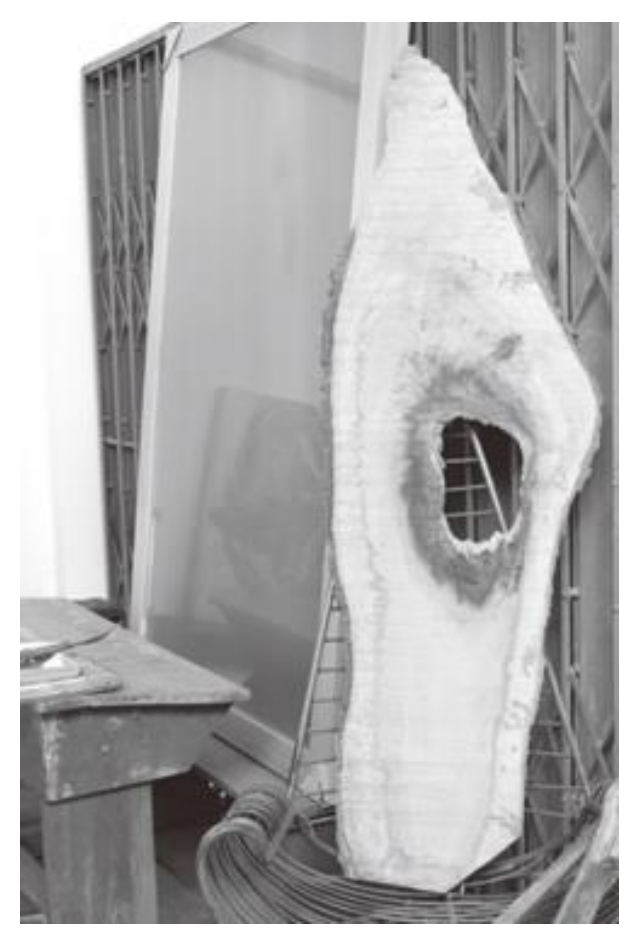

Gambar 4. Sample kayu gelondong bersiluet mengembung pada pohon Sawo (Achras Zapota) dengan tampak luar utuh tapi berlobang di dalamnya. (Sumber: Koleksi Setyo Budi Astanto) 
agar tetap menghasilkan karya desain yang inovatif sejajar kayu gelondong utuh. Kearifan lokal Yogyakarta memberi kontribusi keilmuan pada dunia desain interior bahwa sesungguhnya dengan desain biomimikri, yang menempatkan alam semesta sebagai sumber inspirasi, dengan desain biomimikri yang unggul sampah tidak ada dalam sistem alam semesta, sampah hanya ada dalam pikiran manusia.

\section{Dampak Perilaku Manusia Terhadap kualitas kayu}

Perilaku manusia sangat penting untuk dicermati dalam menjaga kualitas material kayu, perilaku yang menyakiti dan merugikan pohon harus dihindari karena berdampak pada hasil panen kayu yang tidak utuh.Peneliti merasa perlu menyampaikan informasi tentang dampak perilaku manusia terhadap kualitas kayu dalam rangka edukasi masyarakat untuk menjaga dan respek pada sistem alam semesta, sesuai prinsip dasar desain interior berkelanjutan.Kayu berlobang di dalamnya biasanya diakibatkan oleh perilaku manusia selain akibat penyakit yang ditimbulkan hama. Perilaku terbanyak dan sering ditimbulkan manusia adalah memotong ranting terlalu dekat pokok batang pohon, potongan ranting yang terlalu dekat pokok pohon akan mengakibatkan air hujan masuk ke dalam batang utama pohon tanpa proses yang seharusnya, sehingga batang pokok pohon busuk dan menjadi kayu yang berlobang.

Perilaku manusia lainnya adalah melukai pohon dengan kedalaman luka yang berdampak mengakibatkan air masuk ke pokok batang pohon dan pohon menjadi busuk dan menghasilan kayu yang berlobang, Pohon yang dihasilkan dari lingkungan perkotaan biasanya berlubang dan bersiluet dasar mengembung pada batang poko pohon akibat pohon dipaku oleh manusia untuk memasang pengumuman atau reklame. Memaku batang pohon berakibat kualitas kayu berlubang karena terluka dan air hujan masuk ke dalamnya.Pohon yang terluka akibat perilaku manusia tanpa disadari adalah tindakan manusia memaku pohon. Bagaimana siluet kayu pohon utuh saat hidup yang penuh dengan luka tusukan paku, dapat dicermati dan dianalisa dari pemaparan pak Silaban, seorang pejuang lingkungan hidup yang kegiatannya mencabuti paku di pohon-pohon yang tumbuh di kota Bandung. (Liaw, 2005: 79).

Logika dasar pohon yang terluka akan menghasilakan batang kayu yang berlubang sama persis dengan sistem alam semesta yang terjadi pada tubuh manusia yang pernah terluka, sebagai contoh adalah jika tangan manusia pernah mengalami luka patah tulang, maka akan mengalami perubahan bentuk siluet tangan tersebut, biasanya menjadi menonjol atau mengembung akibat kondisi tulang dalam tubuh juga terluka.

\section{Solusi Desain Memanfaatkan Kayu Berlubang Berbasis Desain Interior Berkelanjutan Biomimikri}

Prinsip dasardesain interior berkelanjutan adalah tidak ada sampah dalam sistem alam semesta, kecuali ditimbulkan oleh ulah manusia, maka manusia mempunyai $\mathrm{k}$ ewajiban bertanggung jawab at as perbuatannya tersebut melalui rekayasa desain interior berkelanjutan. Desainer interior berkelanjutan dituntut untuk menghasilkan solusi kreatif yang mampu mencegah terjadinya sampah atau dalam istilah popular biasa disebut Reduce design.

Dari analisa melalui penelitian ini menemukan beberapa data pustaka yang memperlihatkan rekayasa desain sebagai 
solusi mencegah terciptanya sampah baru,konsep kayu sampah karena dalamnya berlobang hanya ada dalam pemikiran manusia.Solusi desain harus diawali dengan tantangan untuk mengoptimalkan material kayu yang ada seoptimal mungkin tanpa menimbulkan sampah baru.

D a t a p u s t a k a e 1 e k t r o n i k memperlihatkan rekayasa desain berbasis pada sistem alam semesta sebagai sumber inspirasi desain.Solusi desain yang tepat mampu menjadikan alam semesta berkaitan kondisi kayu alam sebagai inspirasi desain. Dengan pemahaman baru tentang kearifan lokal Jawa Tengah dalam memilih kayu gelondong, desainer interior dapat memilih kayu seperti kebutuhannya tanpa menimbulkan sampah baru, tidak ada lagi paradigma kayu baik dan kayu buruk, karena semua kayu bisa dioptimalkan berdasar desain i n t e r i o r b e r k e 1 a $n$ j u t a $n$ Biomimikri.(http://www.demilked.com/furni ture-design-glass-wood-table-topographygreg-klassen).

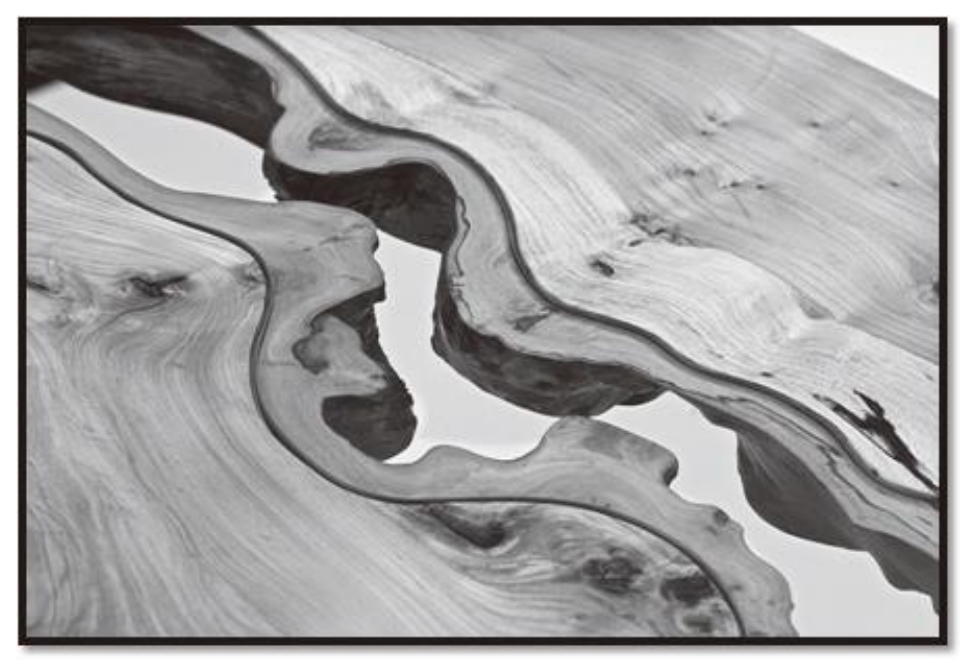

Gambar 5.Rekayasa desain interior menggunakan material dasar kayu yang berlubang (Sumber: http://www.demilked.com/furniture-design-glass-wood-table-topography-greg-klassen).

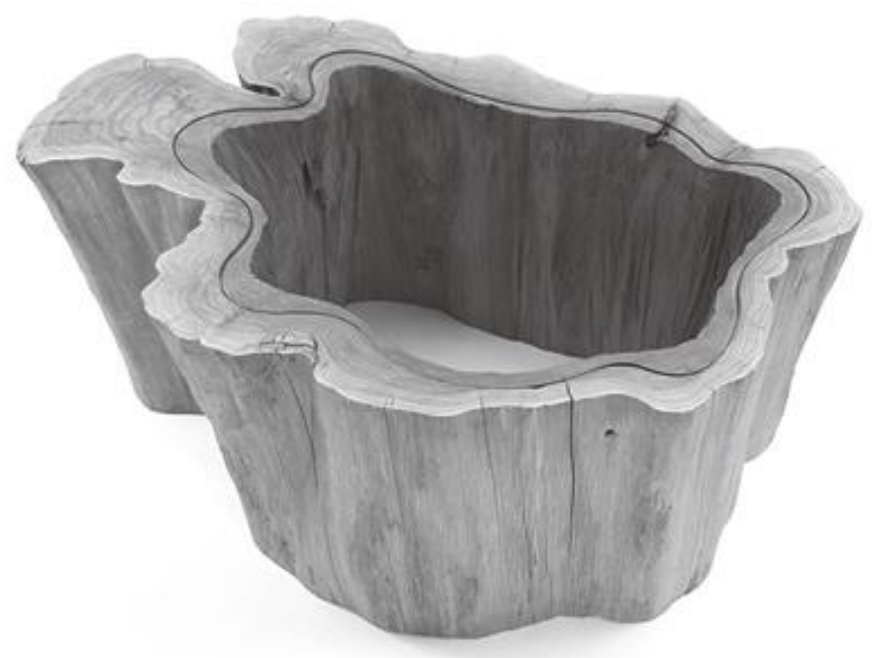

Gambar 6.Rekayasa desain interior menggunakan material dasar kayu berlobang (Sumber: http://www.demilked.com/furniture-design-glass-wood-table-topography-greg-klassen). 


\section{Kesimpulan}

Penelitian berjudul "Kontribusi Kearifan Lokal Yogyakarta Metode Memilih Kayu Bagi Keilmuan Desain Interior Berkelanjutan", menghasilkan temuan bahwa kearifan lokal masyarakat Yogyakarta mempunyai metode tepat guna dalam memilih kayu gelondong, metode melihat siluet tampak luar kayu gelondong dengan berpedoman layaknya bentuk siluet tubuh manusia.Metode warisan nenek moyang yang teruji waktu mampu memprediksi dengan optimal kondisi kayu tanpa harus membelah terlebih dahulu, tujuannya agar mendapatkan kayu balok atau papan sebagaimaterial utama desain interior yang baik atau utuh tidak berlobang.

Cara memilih kayu secara turuntemurun ini sangat efektif dan efisien karena dapat dilakukan semua orang tanpa bantuan alat, berupa logika layaknya tulang tubuh manusia yang pernah patah, kayu yang bulat lurus meruncing wajar adalah kayu bervolume utuh, kayu yang menggembung dan terlihat membesar biasanya berongga karena kayu pernah terluka baik tertancap paku maupun cara memotong ranting yang terlalu mepet pokok pohon, sehingga pohon menghasikan kayu yang busuk di dalamnya.

Temuan penelitian menghasilkan informasi berupa kearifan lokal lisan tentang ciri-ciri fisik kayu yang mengembung atau bersiluet tidak lurus adalahkayu gelondong yang berlobang di dalamnya. Hasil temuan penelitian berkontribusi bagi dunia keilmuan desain interior, sehingga desainer interior bisa melakukan rekayasa desain dengan memanfaatkan lubang alamiah kayu sebagai inspirasi desain secara kreatif,layaknya rekayasa desain interior berkelanjutan Biomimikri karya Greg Klassen yang menjadikan kayu gelondong berlobang sebagai inspirasi desain bukan menganggap kayu sampah hanya karena berlobang tengahnya.

\section{Saran}

Kearifan lokal Yogyakartatentang metode memilih kayugelondongan adalah tipe kearifan lokal lisan, layaknya kearifan lokal lisan lain maka berpotensi besar akanlenyap dan musnah dibawa mati sang penutur seiring perkembangan zaman. Penelitian ini berkejaran dengan waktu, semakin terlambat s e makin ban yak kita kehilangan informan.Peneliti merasa perlu untuk melanjutkan penelitian ini menjadi bahan awal penulisan buku ajar mata kuliah Eko Interior dan Pengetahuan Bahan Desain Interior.

Saran dari hasil penelitian ini adalah memberikan informasi secara mudah dan gampang diterapkan tentang cara memilih kayu, informasi ini akan menjadi pemicu tentang kesadaran tiap individu untuk menghargai dan mengoptimalkan kayu hasil pohon. Pada tataran edukasi informasi cara memilih kayu ini akan menghasilkan kesadaran bersama tentang pentingnya merawat pohon agar menghasilkan kayu yang sesuai kebutuhan desain interior.

\section{Daftar Pustaka}

BSN. (2011), Badan Standardisasi Nasional, Gedung Mandala Wanabhakti, Jakarta

Frick, Heinz. (1997), Pola Struktural danTeknik Bangunan di Indonesia, Suatu pendekatan a $r s$ i t e $k t u r$ Indonesia melalui pattern language secara kontruktif dengan contoh arsitektur Jawa Tengah.Penerbit Kanisius, Yogyakarta. 
Jones, Louise. (2008), Environmentally Responsible Design, Green and Sustainable Designfor Interior Designers.John Wiley \& Sons. Inc, New Jersey.

Komarrudin, M. (2014), Kamus Pertanian Umum. Gramedia, Jakarta

Lausen, J.R. (1969), On Growth Poles, Urban Studies 6: 137-161

Liaw, Ponijan. (2010), Succes and Joy Talks.Elex Media Gramedia. Jakarta

Masters, Elise. (2013), Illustrated Science Dictionary. Grasindo, Jakarta.

Moleong, Lexy J. (2009), Metodologi Penelitian Kualitatif, Edisi Revisi, PT Remaja Rosdakarya, Bandung.

Punch, K.F (2006), Developing Effective Research Proposals, London: Sage Publications

Sawel, G. and Barker, J.R. (2006), Coercien Versus Care: Using Irony to Make Sense of Organitational Surveillance, A c a d e m y of $\mathrm{M}$ a $\mathrm{n}$ a g e m e n t Review,Vol. 31, Issue. 4

Soedarsono, RM. (1999), Metodologi Penelitian Seni Pertunjukan dan Seni Rupa, Masyarakat Seni Pertunjukan Indonesia Bekerjasama dengan Arti, L i n a a $\mathrm{t}$ a $\mathrm{s}$ b a n $\mathrm{t}$ u a $\mathrm{nF}$ or d Foundation, Bandung.

Sutrisno, Hadi. (1980), Metodologi Research $I I$, Fakultas Psikologi UGM, Yogyakarta.

Yin, R.K. (2008), Case Study Research: Design and Methods, London: Sage Publications.

\section{Sumber-Sumber Berupa Penelitian \\ Ilmiah;}

Department for International Development. (1999). "Sustainable Livelihoods GuidanceSheet:Introduction”...http://www.li velihoods.org/info/info_guidancesheets.html \#1.Dodsworth, Simon. (2009), The

Fundamental of Interior Design, AVA Publishing, Switserland.

Birowo, Suminto. Konversi Kayu dan Gergajian terhadap Rumus Kubikasi Kayu, https://sumintoabirowo.wordpress.com/konv ersi-satuan-ukuran-berat-panjang-luas-dani s i / k o n ver s i - k a y u - t e r h a d a p gergajian/,3/01/201503:15:58 AM.

Klasifikasi.Melinjo.Gnetum.Gnemon,.Biolog i.onlinehttp://www.biologionline.info/2014/0 5/klasifikasi-melinjo-gnetum-gnemon.html, 3/03/201503:15:58 AM.

Hasan, Maulana. (2009), Pengujian Kualitas Kayu $\quad B u n d a r \quad J a t i$, (http://repository.ipb.ac.id/bitstream/handle/1 23456789/11228/E09ama.pdf;jsessionid=E3 FCBBDDDD89128C7D0AF24EC8FD06B5 ?sequence=2) $8 / 12 / 201508: 08: 13 \mathrm{AM}$

Perdana, Aulia. (2010), Memahami Rantai P erdaga $n$ ga $n$ Ka y u Jat $i$, http://kiprahagroforestri.blogspot.com/2011/ 01/memahami-rantai-perdagangan-kayujati.html. 8/01/201508:15:51 AM.

\section{Website atau Melalui Internet;}

http://www.demilked.com/furniture-designglass-wood-table-topography-greg-klassen. 3/01/201512:15:51 AM.

http://teknologihutan.fkt.ugm.ac.id/userfiles/ d own load/S N I_ 7533.2 - $2011_{-}$_Kayu_bundar_Bagian_2_Pengukuran_dan tabel_isi_pdf, 13/08/2014 2:18:28AM. https://wholehealthdork.files.wordpress.com/ 2014/03/fracture-healing.jpg. 03/11/2015 12:16:22 AM.

\section{Literatur}

- Unjiya, M.Akrom (2008). Lasem Negeri Dampoawang Sejarah yang Terlupakan. Yogyakarta: Eja 
Publisher.

- Proyek Penelitian Purbakala: Pertemuan Arkeologi III Ciloto 1983. Jakarta: Departemen Pendidikan dan Kebudayaan, 1985.

- Groeneveldt, W.P., Notes on Malay Archipelago and Malacca, Compilet from Chinese Source.

- Kabupaten Rembang dalam Angka Tahun 2005 Data Dekdikbud Rembang

- Pratiwo (1990). The Historikal Reading of Las em. Leuven: KatholikaUneversieit Leuven. http://rumahbatiklasem.com/blog/seja rah-batik-lasem/ 